\title{
Movimientos sociales, nuevas generaciones y el uso de las tecnologías.
}

\section{Entrevista de Camila Ponce Lara ${ }^{1}$ a Carles Feixa ${ }^{2}$}

Entrevista realizada al Dr. Carles Feixa en el marco de la Inauguración del Año Académico del Doctorado en Ciencias Sociales, mención en Juventud, de la Universidad Católica Silva Henríquez (UCSH). La entrevista fue realizada en Santiago de Chile el día 1 de mayo de 2019.3

Camila Ponce: Carles, a partir de los temas que has estado trabajando, particularmente en el tema de generaciones, si pudieras profundizar en aquellos temas, más allá de los elementos enunciados referentes a la tecnología, ¿qué diferencia observas en los distintos contextos globales, los movimientos sociales asociados a esas nuevas generaciones y el tema tecnológico en sí mismo?

Carles Feixa: Yo creo que el concepto de "generación", que tuvo en sociología su peso hace un siglo y que después se reactivó en los años 60, pero que volvió a caer en el olvido, está volviendo a posicionarse en el centro del pensamiento social contemporáneo, en parte por la coyuntura histórica y por los novísimos movimientos sociales. No por casualidad el concepto entra en escena en los años 20, entre la Primera y Segunda Guerra Mundial,

Camila Ponce Lara es directora del Doctorado en Ciencias Sociales, mención en Juventud, e investigadora en el Centro de Estudios en Ciencias sociales y Juventud de la Universidad Católica Silva Henríquez. Esta entrevista se inscribe en el Proyecto Fondecyt Iniciación $\mathrm{N}^{\circ} 11170930$.

2 Carles Feixa es académico en la Universidad Pompeu Fabra, Doctor en Antropología Social por la Universidad de Barcelona y Doctor Honoris Causa por la Universidad de Manizales, Colombia. Especialista en los estudios sobre culturas juveniles y generaciones, ha realizado importantes publicaciones, entre las que destacan: De jóvenes, bandas y tribus (Barcelona, Ariel, 1998, $5^{a}$ ed. 2012), Global Youth? (Londres y Nueva York, Routledge, 2006), Youth, Space and Time (Boston y Leiden, Brill, 2016) y La imaginación autobiográfica (Barcelona, Gedisa, 2018).

3 La entrevista fue transcrita por el tesista Fondecyt, Felipe Cárcamo. 
un momento en que, por una parte, las guerras mundiales crean una fractura generacional muy marcada, que suscitan la aparición de una conciencia generacional. Las personas que regresan del frente tienen la conciencia de haber compartido, en este caso, una experiencia traumática, y algunos intelectuales la elaboran en términos académicos. Pero en ese momento, en los años 20, hay unas teorías que no se aplican en la investigación social, porque la edad y la juventud no se consideran como un objeto de estudio pertinente.

El segundo momento de irrupción del concepto de "generaciones" es en los 60, obviamente vinculado a la explosión de los movimientos estudiantiles y contraculturales. Así como la primera formulación, en los años 20, gira en torno a relevo generacional: una generación sucede a la otra, hay progreso, pero hay un relevo más o menos plácido; en cambio en los 60 la formulación gira en torno a la brecha o conflicto generacional. Los jóvenes primero se diferencian a través de la cultura, que es parte del curso que plantearemos en la Universidad Católica Silva Henríquez, la emergencia de la cultura juvenil, de la música, del ocio, de las modas, que construyen su espacio propio aparte de los adultos. Y después del 68, o contemporáneo al 68, ya van más allá, y hay un intento de ruptura, hay un intento de brecha en términos simbólicos, de "matar al padre", es un conflicto edípico a nivel social. Por tanto, supone que ya no es un relevo pacífico, sino que es una lucha de generaciones: hay teorías, digamos pseudomarxistas, que plantean la substitución del conflicto de clases por el conflicto generacional. En los años 70, ya con la decadencia de los movimientos de protesta, la integración al sistema y con la llegada de la crisis económica y el paro juvenil, el concepto de "generación" queda un poco en el olvido y dominan otros aspectos. Por ejemplo, en el caso de los estudios sobre la juventud, la prioridad es el estudio de las transiciones y trayectorias juveniles al mundo adulto, o los estudios sobre culturas juveniles.

En la última década, más bien en los años 2000, a raíz de la emergencia de las nuevas tecnologías e internet, vuelve a poner- 
se de moda el término "generación", en este caso muy vinculado a las innovaciones en la tecnología, que presuponen que la noción clave es la de "vuelta" o "giro generacional", es decir, que los jóvenes pasan por delante de las generaciones adultas en el acceso a las innovaciones más importantes y, por tanto, actúan como frente de vanguardia que va experimentando con algunas nuevas tecnologías: el chat, los SMS, el celular, los smartphones, las tabletas, el WhatsApp, Facebook, Instagram... Casi todas las innovaciones de las tecnologías en los últimos 20 años han sido primero experimentadas en grupos adolescentes-juveniles, y las que han tenido éxito se trasladan luego al mundo adulto, a las generaciones más ancianas, y cuando son apropiadas por los adultos los jóvenes exploran nuevos territorios.

El uso actual del concepto de "generación" a veces es un poco superficial y muy vinculado a los cambios tecnológicos que no siempre coinciden con cambios generacionales. Para que exista una generación, decía Mannheim (1993) - y Bourdieu lo retomó-, debe haber no solo un hecho generacional que marque una ruptura o una conciencia generacional, sino que debe haber sobre todo cambios estructurales en la sociedad. Como decía Bourdieu, debe haber cambios en el modo de generación social de los actores, es decir, los modos de generación o de construcción social de la juventud deben incorporar algún cambio. Y en estos últimos 20 años sí se han producido cambios profundos, en parte por el alargamiento de la juventud, los cambios en la educación y en el acceso al trabajo, o toda la cultura virtual que supone una modificación de la noción de "generación". En este caso, el acontecimiento generacional podríamos decir que es el de la revuelta de 2011 y post 2011, que corresponde a las guerras mundiales o las revueltas del 68. La diferencia es que son procesos mediados por la tecnología y, al mismo tiempo, la globalización ya no es un hecho externo como era en el pasado, sino más bien un hecho que los jóvenes viven directamente (Leccardi y Feixa, 2011).

CP: Bueno, a partir de la idea de las "acampadas", que has desarrollado bastante, que es muy interesante y que podemos 
verlas en estos movimientos de plazas, en la primavera árabe o movimientos de indignados de Europa, pero que en el caso de América Latina no están presentes este tipo de experiencias. Por otro lado, otros autores han hablado de estas movilizaciones de movimientos de plazas; por ejemplo, Pleyers (2017) habla de ese concepto; otros, como Bringel (2013), prefieren hablar de una nueva ola, de este nuevo ciclo de movimientos sociales; otros simplemente lo enmarcan, como diría Touraine (2006), en nuevos o nuevos nuevos movimientos sociales. ¿Tú cómo prefieres llamarlos? ¿Prefieres utilizar este concepto de "acampada" o te acomodan más estos otros tecnicismos de los conceptos de los movimientos sociales?

CF: Digamos, los términos no hacen la cosa, es la cosa quien ayuda a reconceptualizar, y los términos o asunciones de los conceptos nos ayudan a entender qué cambios ha habido. En este sentido, fue con un antropólogo norteamericano, Jeff Juris, quien había hecho su tesis en torno a movimientos antiglobalización en EE.UU., y con él hace 15 años propusimos el concepto "new, new, social movements" para referirnos a los movimientos sociales en red, a los movimientos sociales de la era digital (Feixa, Costa y Saura, 2002; Feixa, Pereira y Juris, 2009; Juris, Feixa y Pereira, 2012). En castellano la traducción serían "novísimos movimientos sociales"; la traducción literal — "nuevos, nuevos"— no suena bien, porque es una redundancia, porque siempre todo es muy nuevo, pero la propusimos para diferenciar el tipo de movimientos que estaban surgiendo en el nuevo siglo de los llamados "nuevos movimientos sociales" de los años 60 (como el ecologismo, el feminismo, el movimiento gay-lesbiano), y de los "viejos movimientos sociales" desde la revolución industrial hasta las guerras mundiales (como el movimiento obrero, el anarquista, el sufragista, etc.). Los nuevos son los que surgen en el contexto del Estado de Bienestar y la sociedad del consumo, digamos de los años 60, y los novísimos los que estaban surgiendo en 2002-2003, eran los que, tras la caída del muro de Berlín, luchaban contra el neoliberalismo y sobre todo contra los llamados movimientos 
altermundialistas o la antiglobalización. Solamente que desde el año 2000 para acá ha habido una serie de cambios.

Con Jeff pensábamos que hay que diferenciar estos movimientos, principalmente por el uso de internet como forma de comunicación y también como táctica de lucha. Ya no solo se lucha en el espacio público o usando los medios tradicionales, como los periódicos o el grafiti, como sucedió en mayo del 68, sino que la protesta se organiza y acompaña a través de distintas interfaces, que primero eran blogs o correos electrónicos y después fueron las redes sociales, Twitter y las distintas tecnologías en la que actores y activistas siempre van por delante de las fuerzas que intentan reprimirlas. La antiglobalización tiene distintas fases: una fase de protesta contra las grandes corporaciones multinacionales (lo más visible es Seattle); después la construcción de alternativas, que es Porto Alegre, pero que no da el paso hacia una institucionalidad hasta que la crisis financiera internacional de post 2008 ofrece un nuevo panorama que explota en el 2011. Eso de algún modo sigue la tendencia de lo que habíamos caracterizado como "novísimos movimientos sociales": ya no es solo la clase o el género lo que importa, la edad y generación vuelven a ser significativas, vuelve a ser un ser un movimiento más reformista, con cambios concretos en la sociedad: como la justicia ecológica, la equidad económica, el conflicto norte-sur también es relevante; y que son movimientos transgeneracionales: no es solo la juventud la que se moviliza, sino que hay alianzas de grupos etarios. Solo que en la primera fase el activismo es muy minoritario, y es a partir de 2011 cuando se produce una cadena de revueltas que se globaliza y se generaliza.

Es verdad que no en todos los sitios hay acampadas, pero el mismo análisis en "Ocuppy Boston" muestra que hay un cansancio con el "clicktivismo" digital y hay una vuelta al "face to face", a la plaza. Eran acampadas no en cualquier sitio, sino en el centro de las ciudades. Es verdad que en Colombia el movimiento estudiantil no tuvo acampadas, pero después del referéndum por la paz sí hubo acampadas en Bogotá y en Medellín, aunque la 
represión policial las impedía. En África del Norte tomó por sorpresa y en Europa la represión policial fue más tolerante. Pero sí que había el deseo del contacto cara a cara, el deseo de la calle, de la ciudad, y el intento de visibilización y revueltas o movimientos que reivindicaban la crítica al concepto de "juventud" vigente, a este largo aliento de esta juventud sin futuro o, más que sin futuro, un futuro peor que el que habían prometido: sería el horizonte de la protesta. Y lo que aunaba o hacía semejante era el hecho que eran jóvenes en el sur, en el norte, este y oeste, múltiples y diferentes entre ellos (Feixa y Nofre, 2013).

CP: Y sobre lo que estamos viendo en el momento actual, más bien en 2018, todos estos movimientos que comienzan a emerger: movimientos feministas en Chile y Argentina, los pañuelazos verdes, en Brasil el movimiento de EleNão contra Bolsonaro, ¿te parece que corresponde a una fase tardía de los movimientos de 2011 o representa otro nuevo ciclo político de movilizaciones? ¿Una nueva ola feminista? ¿Cómo podríamos llamarlo?

CF: Yo creo que es la tercera ola. El 1.0 o lo que yo denomino la "generación @", dura de 2000 a 2010, aproximadamente, es la primera generación de internet, todavía en un contexto de crecimiento económico y de crítica a las corporaciones transnacionales y al neoliberalismo de forma clásica. La segunda ola son los movimientos indignados, que corresponden a internet 2.0, a redes sociales: internet, Facebook, Twitter, Microblogging... (Feixa, 2010)

CP: Es el Hashtag.

CF: La generación Hashtag (Feixa, 2010; Feixa, FernándezPlanells y Figueras, 2014), que corresponde a todas las movilizaciones y la coyuntura es la crisis económica y moral. Y yo creo que ahora estamos entrando en la tercera ola, el contexto de la salida de la crisis con distintas identidades, más neoconservadoras, que han suscitado la nueva extremaderecha. Y una parte del tema de género como algo central en esta nueva fase; en lo tecnológico, yo denomino esto de manera provisional esta ter- 
cera fase o esta tercera ola, la generación "blockchain", es una tecnología digital que en origen significa cadena de bloques o de datos, se creó para las monedas virtuales, como el bitcoin, para asegurar la fiabilidad de estas, y corresponde a diferentes teorías pero viene a corresponder al llamado web 3.0, al internet emocional, al internet individualizado, ya no tan masivo, o la superación de las redes sociales y el énfasis en lo más personal y en la interconectividad a la escala planetaria. Y, por otra parte, a los intentos de una economía colaborativa, de una cultura colaborativa, de crear nuevas modalidades de convivencia y trabajo que ya no responden al sistema industrial clásico, pero tampoco a una sociedad igualitaria, socialista, sino más bien a un tipo de economía de escalas colaborativas con experiencias como el coworking, el cohousing, en la que ya los jóvenes hacen de la necesidad una virtud, transforman su precariedad en necesidad de cooperar con otros para sobrevivir. De algún modo, es la vuelta a lo comunitario, pero con la máxima inversión tecnológica, en la que los jóvenes siguen siendo pioneros y en la que siguen explorando nuevos territorios. Y eso en el plano del movimiento social se concreta al menos en estos dos tipos de movimiento: por una parte, en el movimiento neoconservador, que Pleyers (2019) está trabajando, que son tan tecnológicos como el resto, pero que cambian las formas, en el fondo es un repliegue hacia el pasado, hacia el miedo frente a la novedad, frente al extranjero, frente a lo diferente, y de algún modo la vuelta a la seguridad, a aferrarse a estructuras sociales e ideológicas primarias. En cambio, el nuevo movimiento feminista es distinto. Así es como el movimiento feminista tiene tres periodos: el movimiento clásico serían las sufragistas, que no dejan de ser un movimiento bastante elitista y se centran en reivindicar algunos derechos formales, el derecho al voto clásico; en los 60 de los nuevos movimientos sociales surgen los movimientos feministas que conocemos ahora y se centran en reivindicar la libertad sexual, la libertad de expresión de las mujeres, el acceso al espacio público, etc. En esta tercera fase del movimiento fe- 
minista no por casualidad la demanda central es la lucha contra la violencia experimentada por las mujeres, el llamado feminicidio. De hecho, también un par de movimientos juveniles se conectan con el feminicidio, con la violencia que antes era tolerada, violencia física, violaciones sobre todo, y violencia moral, acoso que sufren las mujeres. Y significativamente quienes están liderando, quienes están siendo la vanguardia de estos cambios son las mujeres más jóvenes: las adolescentes que no fueron muy activas en los movimientos indignados, pero que descubren en este movimiento algo que les toca, es una relación muy directa y muy cotidiana de igualdad y de equidad con sus coetáneas (Sánchez-García, Ballesté y Feixa, 2019).

Por lo tanto, digamos, estos movimientos blockchain tienen género, se viven en clave de género. Son movimientos de género y generación. Ahora, estos están en una fase muy exploratoria, el origen en este caso fue América Latina, fue el origen de \#NiUnaMenos. Bueno, yo estuve en la de Rosario en 2015, y en la de Lima en 2016, que fue muy grande, pero en México juega un papel importante y de ahí pasa a Estados Unidos, que como siempre lo hace viral con el \#MeToo (Iniesta y Feixa, 2019). Se juntan de algún modo un movimiento feminista con un movimiento juvenil, hay una doble categoría. Y consigue la hegemonía, porque siempre el movimiento feminista estuvo presente en los movimientos sociales, pero tenía un papel secundario: ahora es quien marca la tendencia y la ruptura, que va por una parte a lo tecnológico, a Instagram, los blogs y las redes, pero por otra parte a lo personal a lo emocional, a lo más privado, al internet de las emociones, que es parte del blockchain. Algo parecido sucede con el novísimo movimiento ecologista como reacción al cambio climático, el \#FridaysForFuture, liderado por una adolescente sueca, que jóvenes de todo el mundo han viralizado convirtiéndolo en una marca generacional.

CP: Sobre el sujeto, yendo a lo que decías en la pregunta anterior, acerca de esta generación más individualizada. Por ejemplo, en las movilizaciones de 2011 veíamos que los activistas eran pro- 
tagonistas, ganaban portadas. Fueron protagonistas de la portada del Time y del The Guardian.

CF: Tengo la foto del Time, cuando escogió como protagonista del año 2011 a "The Protester", que además era una representación híbrida entre masculino y femenino, oriental y occidental, con bandana.

CP: Bueno, mi pregunta apunta al sujeto activista, pero también al hecho de que algunos tienen líderes relevantes en América Latina, con líderes estudiantiles, organizados, versus estos movimientos de plazas sin organización y mucho más horizontales. ¿Qué pasa hoy día? Porque vemos que están con fuerza, ya no necesariamente en estas redes sociales que veíamos antes, en 2011, pero sí con una individualización importante y en otro tipo de plataformas, como Instagram, en las que están mostrando su vida y sociabilizando y aprendiendo de otros activistas, como el caso feminista, a volverse y a aprender de feminismo también. Entonces, es importante ver este sujeto, un poco distinto, y que ya no está este líder omnipresente en las movilizaciones. ¿Cómo ves a este sujeto? ¿Desaparece completamente?

CF: No, es un liderazgo más colectivo, más grupal, no está desorganizado, no es una masa amorfa. Pero, lo mismo que el blockchain, la tecnología se basa en la cadena, pero es una cadena con estructura, que está anclada en algún punto y alguien la mueve; del mismo modo, en estos movimimientos el liderazgo se ejerce a partir de pequeños grupos que se conectan entre ellos. Tal vez desde fuera no los vemos porque escapan a la mediatización clásica, pero en cambio sí que buscan la micromediatización, sobre todo de estas microredes como Instagram, donde hay un cierto narcicismo, es un narcisismo que pasa por lo individual, que es la selfie, el joven que necesita retratarse a sí mismo, a un narcisismo del grupo, del colectivo; de ahí las marchas del 8-M de los últimos años, en las que todos iban con sus móviles y se iban retratando constantemente. Hay una obsesión por fijar la imagen, pero fijar no tanto la imagen para que vaya en televisión 
y que todo el mundo te conozca y te hagas famoso, sino para autoafirmarse dentro del colectivo.

Ahora bien, es verdad que hay un dilema, un reto, y es que en algún momento este liderazgo debe generar algún tipo de estructura, de organización, si no es así la concreción del activismo no va más allá. Y eso todavía no ha sucedido, excepto en algún caso donde se han implantado algunas reformas en la legislación o, sobre todo, en la sensación de impunidad que tenían. Por ejemplo, en los casos de violencia de género no ha habido una forma de organización más colectiva, más cooperativa, que traslade esto a la política o a la vida crítica, y eso implica buscar un tipo de liderazgo no tan vertical, más horizontal, pero al mismo tiempo que transmita las decisiones o propuestas que surgen de estos movimientos. Esto ya sucedió con el movimiento en el 68, que al principio no querían líderes, pero al final los hubo, era el modelo de las asambleas y acaban habiendo líderes. Ahora no hay asambleas o no las vemos, hay asambleas más pequeñas, sobre todo en las movilizaciones de las marchas colectivas y que se conectan con lo que denominamos "microfeminismo", de pequeños grupos o colectivos, algunos LGTBI que están surgiendo y con gran presencia de los adolescentes de la generación blockchain, que es la que ahora está entrando y está cumpliendo 20 años, que es la próxima generación (Feixa y Pires, 2019).

CP: Quería preguntarte sobre los $\mathrm{NiNi}$, porque parece que hay ciertos desfases entre lo que observamos en Europa y lo que vemos acá. A veces hablamos también de una generación idealista, que realmente no alcanza a entrar al mercado del trabajo, que además está en crisis, pero justamente acá, en un pequeño estudio que hicimos (Cavieres, Ponce y Gómez, en prensa), pudimos observar que esos NiNi eran jóvenes que se autoexcluían en algunas ocasiones, o que estaban excluidos también por el sistema. Unos que querían seguir su vida y encontrarse a sí mismos, que tenían una búsqueda personal; la crisis acá va más allá de la crisis económica, puesto que podemos ver un sistema estructural, fragmentado. Por otro lado, están los jóvenes que realmente están 
excluidos del mercado laboral y que no pueden entrar porque no cumplen con ciertas condiciones. Un joven mucho más marginal, mucho más outsider, si lo podemos llamar así, versus otro que cumple los cánones más europeos y sí está en esta búsqueda de sí mismo y se abren dos caminos, dos líneas posibles.

CF: Digamos que la etiqueta en sí no dice nada, pero que se puede utilizar y darle la vuelta. Esa vuelta nos ayuda a entender cómo ha cambiado la transición de la educación al trabajo, ese es el tema. A la salida de la crisis, en la sociedad posdigital, la transición de la escuela al trabajo ya no es algo lineal sino algo muy pendular, y hay un sector que en esta transición se pierde: son los que llamamos NiNis, quienes, a la salida de la escuela secundaria, no encuentran un encaje en el sistema productivo, aunque dentro de esa categoría obviamente hay una diversidad de personas: muchachas que se quedaron embarazadas, que se casaron; jóvenes migrantes o marginados, o los que se toman un año sabático antes de entrar en la universidad. Yo creo que, quizás voy a decir algo provocativo, pero no es malo siempre y cuando sea temporal, siempre y cuando sea una manera de plantearse la vida y el futuro y no seguir la inercia del sistema. Aunque curiosamente lo más significativo no son los NiNi sino los SiSi: se vuelve a esa figura del joven que trabaja y estudia, ya no es una figura pura; era una figura híbrida básicamente. Los jovenes obreros del pasado, que estudian de noche para ir con la idea de la educación como vía de ascenso social, con los bachilleratos nocturnos o a distancia, vuelve a esa figura en la secundaria y en la universidad. Antes la inmensa cantidad de estudiantes que había solo estudiaba. Ahora hay muchos que están estudiando y trabajando, tienen trabajos temporales, parciales, provisionales, y van aprendiendo de esa experiencia a lo largo del tiempo. Claro, la dificultad es que, en Europa, lo que se está produciendo es una brecha creciente entre el modelo del centro y el del norte de Europa, donde no hay NiNis, pues allí a los 18 años o vas a la universidad o tienes ayudas del Estado del Bienestar, o trabajas con sueldos que te permiten una autono- 
mía y ya no seguir con los padres: tanto los que trabajan como los que estudian, muy pocos de los que siguen en una carrera siguen viviendo con los padres, sino que tienes que vivir por tu cuenta. En cambio, en el sur de Europa, el modelo familista, la ausencia del Estado de Bienestar y el tipo de trabajos que se dan provocaron que se creara el modelo del NiNi, ya sea como realidad minoritaria, como reflejo o metáfora de la precariedad laboral, pero sobre todo como justificación ideológica y moral, como estigma social para denigrar a esta generación perdida, a esta generación entremedio, que en el fondo es esta generación que se plantea para qué estudiar si el título no me va a servir de nada. Es en el fondo una opción estratégica o realista de que la educación ya ha dejado de ser una promesa de ascenso social, un territorio de paso para mejorar, y se ha convertido en un territorio de reclusión, en un parking, en una condena a otro tipo de precariedad (Cabarés, Pardell y Feixa, 2018).

CP: Muchas gracias Carles.

\section{Referencias}

Bringel, B. (2013). O Brasil na geopolítica da indignação global. Brasil de Fato, 27, 42-53.

Cabasés, M. A., Pardell, A. y Feixa, C. (Eds.). (2018). Jóvenes, trabajo y futuro. Perspectivas de la Garantía Juvenil en España y Europa. València: Tirant lo Blanch.

Cavieres, H., Ponce, C. y Gómez, J. (en prensa). "Más allá de los “NINIS": Relación entre juventud, exclusión social y trabajo en el Chile actual". Revista Convergencia. Universidad Autónoma del Estado de México.

Feixa, C. (2000). Generación @. La juventud en la era digital. Nómadas, 13, 76-91.

Feixa, C. y Pires, L. (2019). Da Geração @ à Geração Blockchain. A juventude na era postdigital. Revista Textura, 21(48).

Feixa, C. y Nofre, J. (Eds.). (2013). \#GeneraciónIndignada: Topías y Utopías del 15M. Lleida: Milenio.

Feixa, C., Fernández-Planells, A. y Figueras, M. (2016). Generación Has- 
htag. Los movimientos juveniles en la era de la web social. Revista Latinoamericana de Ciencias Sociales, Niñez y Juventud, 14(1), 107-120.

Feixa, C., Costa, C. y Saura, J. (Eds.). (2002). Movimientos juveniles: de la globalización a la antiglobalización. Barcelona: Ariel.

Feixa, C., Pereira, I. y Juris, J. J. (2009). Global Citizenship and the 'New New' Social Movements: Iberian connections. Young, 17(4), 421-442.

Feixa, C., Saura, J. R. y Costa, C. (2002). De jóvenes, movimientos y sociedades. En C. Feixa, J. R. Saura y C. Costa (Eds.), Movimientos Juveniles. De la globalización a la antiglobalización (924). Barcelona: Ariel.

Iniesta, M. y Feixa, C. (2019). Del \#13A al \#8M: una lectura en clave generacional. En G. Salazar y C. Ilizarbe (Coords.), Activismos juveniles y derechos humanos en Perú. Lima: Coordinadora Nacional de Derechos Humanos.

Juris, J., Pereira, I. y Feixa, C. (2012). La globalización alternativa y los novísimos movimientos sociales. Revista del Centro de Investigación, Universidad La Salle, 10(37), 23-39.

Leccardi, C. y Feixa, C. (2011). El concepto de generación en las teorías sobre la juventud. Última Década, 18(34).

Mannheim, K. (1993). El problema de las generaciones. Revista Española de Investigaciones Sociológicas (REIS), 62, 193-242.

Pleyers, G. (2017). Movimientos de las plazas en el decenio 2010. Movimientos, 1 (1), 81-105.

Pleyers, G. (2019). A modo de conclusión: más allá de los nuevos movimientos sociales. En J. Sánchez-García, E. Ballesté y C. Feixa (Eds.), ¿Qué fue de la primavera indignada? Lleida: Milenio.

Sánchez-García, J., Ballesté, E. y Feixa, C. (2019). ¿Qué fue de la primavera indignada? Lleida: Milenio.

Touraine, A. (2006). Los movimientos sociales. Revista Colombiana de Sociología, 27, 255-278. 